Riaño, Yvonne (2015): "Minga Biographic Workshops with Highly Skilled Migrant Women: Enhancing Spaces of Inclusion". In: Qualitative Research (QR), Special Issue on Feminist Participatory Methodologies: pp. 1-13. Sage.

\title{
Minga Biographic Workshops with Highly Skilled Migrant Women: \\ Enhancing Spaces of Inclusion
}

Yvonne Riaño

\begin{abstract}
This paper proposes the notion of 'marginalised elites' to examine highly skilled migrant women, a group that has been neglected by feminist participatory research. It asks what principles and methods can be used towards inclusive practices in studies of migration and social exclusion. The paper contributes to the literature by designing and critically evaluating the method of participatory Minga workshops, which create inclusionary spaces of data collection and critical analysis with highly skilled migrant women living in Switzerland. Using this case study, the paper questions notions of privilege, power and positionality commonly used in feminist participatory approaches. Minga Biographic workshops enhance spaces of inclusion, become 'spaces of personal transformation', question the perceived inferiority of migrant women, and produce original scientific insights on social exclusion. These results point to the role of academics as facilitators of personal transformation, and the need to closely consider the added scientific value of feminist participatory methodologies.
\end{abstract}

Keywords: migration, highly skilled migrants, migrant women, elites, social exclusion, spaces of inclusion, feminist participatory methods, biographic workshops, power, positionality.

\section{Introduction}

The migration of highly skilled migrant women is a phenomenon of growing significance. In the past decade, the number of migrant women with tertiary education in OECD countries rose by 80 per cent (IOM/OECD, 2014). Researchers, however, tend to focus on unskilled women in the global Northdomestic labourers, for example — rather than on highly skilled women attempting to obtain skilled positions in the global labour market (Erel 2009). Accordingly, all migrant women in Swiss society are stereotypically perceived as uneducated, oppressed, and/or needing support from educated Western feminists (Riaño 2011). Having myself been faced with that devaluing gaze (I moved from Colombia to Switzerland in the 1980 s for postgraduate studies), from 2005 to 2007 I initiated a research project investigating the experiences of social integration and social exclusion of highly skilled migrant women 
Riaño, Yvonne (2015): "Minga Biographic Workshops with Highly Skilled Migrant Women: Enhancing Spaces of Inclusion". In: Qualitative Research (QR), Special Issue on Feminist Participatory Methodologies: pp. 1-13. Sage.

in an attempt to fill this former research gap and change the perception of migrant women as deficient or inferior. However, the question remained: how can social exclusion be studied from a non-exploitative perspective (cf Cahill 2007)?

Feminist geographers who plead for just methods characterised by less hierarchical power relations in research echo this purpose. Their goal is to conduct research with rather than on the study subjects (Rose 1997; Sharp 2005; Jaggar 2008). Postcolonial researchers introduce new dimensions of racism, colonialism, and oppression, invite us to reflect on the colonial origins of academic imaginaries, and call for researchers to decolonize methodologies (Mohanty 1991; Tuhiwai Smith, 1999). Despite intense theoretical discussion, however, literature on how to operationalize the purposes of feminist and postcolonial approaches remains limited (Pain et al 2011; Riaño 2011).

In seeking to clarify what constitutes inclusionary methods when working with highly skilled migrant women, I encountered virtually no academic literature explicitly addressing that topic. Participatory researchers neglect highly skilled migrant women living in countries of the North, and migration scholars rarely develop and implement inclusive methodologies. Available studies concentrate on vulnerable groups that are more powerless than academics, such as undocumented migrants (Cahill 2010), rural migrants (Letiecq and Schmalzbauer 2012) and domestic workers (Francisco 2014). This paper contributes to filling this research gap by designing and critically evaluating the method of Minga biographic workshops, conceived to create inclusionary spaces of data collection and critical analysis with highly skilled migrant women living in Switzerland.

The article is structured in three parts. The first raises the issue of how to define highly skilled migrant women and discusses the implications for positionality, a key notion of feminist research. The second part asks what principles and suitable methods can be applied to create inclusionary spaces of knowledge, and describes the Minga biographic workshop method in detail. The third part reflects critically on the potential — and challenges - of these workshops. The conclusion questions what can be learned from the proposed methodology. 
Riaño, Yvonne (2015): "Minga Biographic Workshops with Highly Skilled Migrant Women: Enhancing Spaces of Inclusion". In: Qualitative Research (QR), Special Issue on Feminist Participatory Methodologies: pp. 1-13. Sage.

\section{Highly skilled migrant women and positionality}

Neal and McLaughlin (2009) make a distinction between researching powerful and non-powerful subjects and alert us to the difficulties of creating inclusive research relationships with powerful elites. If highly skilled migrants are understood as 'transnational elites' (Beaverstock 2005), are highly skilled migrant women also elite? Policymakers who assume that a higher level of education automatically assures successful labour market integration echo this understanding, but does it reflect the actual experiences of highly skilled migrant women? Analysis of the 2010 Swiss Labour Force Survey shows that they are the most disadvantaged group among native and non-native highly skilled individuals, having the lowest employment rates, lowest average income levels, and employment levels incommensurate with their qualifications (Riaño et al 2015). This is an interesting paradox: highly skilled migrant women may be understood as elites in educational terms, but their position in the Swiss labour market is marginal. Therefore, I argue for a geographically relational notion of power when defining elites (cf Smith 2006). Highly skilled women in positions of power in their native countries often experience a loss (or reduction) of power in the society to which they migrate. Accordingly, categories such as 'powerful elites' and 'powerless others' (Smith ibid) are meaningless without considering the extent to which elites can transfer their skills and power across borders (cf Riaño 2011; Neal and McLaughlin 2009). In the case of highly skilled migrant women I propose the term 'marginalized elites'.

Working with 'marginalised elites' raises the issue of positionality. Feminist geographers have argued that 'a researcher's positionality (in terms of race, nationality, age, gender, social and economic status, sexuality) may influence the "data" collected and thus the information that becomes coded as "knowledge" (Madge 1993: 296). In this debate, academics have been portrayed as 'privileged' with regard to their research subjects (Kobayashi 1994), creating positional separation. Working with 'marginalised elites' shows that this assumption is not necessarily true. In terms of access to higher education my research partners were as privileged as myself. My gender, migratory experience, and Otherness also put me in a position of commonality with them. This shows the need for a more complex understanding of 'privilege' and power; pairing subject groups and researchers with similar educational levels may provide new avenues for that purpose. Feminist geography and participatory research have disproportionately focused on vulnerable and less educated populations, leaving the potential of coproducing knowledge with elites and marginalised elites insufficiently exploited. 
Riaño, Yvonne (2015): "Minga Biographic Workshops with Highly Skilled Migrant Women: Enhancing Spaces of Inclusion". In: Qualitative Research (QR), Special Issue on Feminist Participatory Methodologies: pp. 1-13. Sage.

My position of commonality with the research participants facilitated the task of finding research partners, and my project collaborator Nadia Baghdadi shared a similar positionality due to her migrant background. Many highly skilled migrant women responded quickly and positively when invited to become research partners, viewing our migrant backgrounds as an asset in understanding their own experiences of social exclusion. Contrary to warnings about the difficulties of creating less hierarchical research relationships with elites (Neal and McLaughlin 2009), in this case it was relatively easy to implement the principles of cooperation and reciprocity with our research partners.

However, commonality is only one side of the story, as my positionality also contained elements of difference. For some potential participants my status as an academic represented our primary difference. Some of the women contacted refused—or were reluctant to-collaborate because of mistrust in academic institutions. In their view, academics ignore migrant women as potential research partners and often conduct exploitative research. A similar response was initially found among the two migrant NGOs that were contacted as potential project partners, but this resistance contrasted with opinions of other women who saw my academic status as an advantage. In their view, it lent academic legitimacy to the stories of exclusion they felt policymakers should recognize.

What lesson do we draw from this in considering positionality? In feminist debates, researchers are divided between having 'more commonalities' or 'less commonalities' with research subjects, which separate or bring them closer (Doyle 1999). I propose transcending this dualism by acknowledging both commonality and difference in the process of negotiating research partnerships.

\section{Partnership principles and Minga workshops}

What principles should guide research partnerships that create inclusive spaces of knowledge production? Six principles are proposed (see Table 1), starting with reciprocity. For Kindon et al (2010:1), participatory approaches imply replacing 'an "extractive", imperial model of social research with one in which the benefits of research accrue more directly to the communities involved.' But what are 'accrued benefits'? In my view, the key to achieving reciprocity is shared knowledge. Research is a collaborative process where both partners (academics and research participants) reflect on-and learn from-the research process, thus benefitting from the second principle, mutual learning. Third, mutual recognition; for a research partnership to be successful both partners need to be recognised as experts. Some have 
Riaño, Yvonne (2015): "Minga Biographic Workshops with Highly Skilled Migrant Women: Enhancing Spaces of Inclusion". In: Qualitative Research (QR), Special Issue on Feminist Participatory Methodologies: pp. 1-13. Sage.

gained expertise in academic spaces, others in everyday spaces of experience, some in both. The fourth principle is dialogic engagement, or the systematic exchange of knowledge among partners. This has long been recognised as essential for any participatory project (Freire 1970). Fifth, researchers also hint at the principle of personal transformation by stating that processes of collective reflection open up critical insights among individuals (e.g. Cahill 2010).

Finally, access to academic spaces is an often-overlooked principle of research partnerships. In conventional research, academics collect data in the 'field'-i.e. the places inhabited or frequented by research participants - and then conduct data analysis in academic spaces. This spatial separation creates inequalities in research: while academics achieve an understanding of both the research field and academia, research participants are unable to access the latter. In participatory projects the exchange between academics and research participants also takes place away from academic sites. More debate is necessary about the implications of where knowledge is produced for what kind of knowledge. Kesby et al (2010) illustrate that research participants are often invited into pre-designed participatory spaces that restrict initiative and co-opt them into supporting the status quo. Integrating academic sites into the dialogic exchange between academics and research partners must be considered.

\section{Table 1. Principles for research partnerships}

\begin{tabular}{|ll|}
\hline 1. & Reciprocity \\
\hline 2. & Mutual learning \\
\hline 3. & Mutual recognition \\
\hline 4. & Dialogic engagement \\
\hline 5. & Personal transformation \\
\hline 6. & Access to academic spaces \\
\hline
\end{tabular}

Once proposed, how can these research principles be operationalized? Also, what methods are adequate to co-produce knowledge with highly skilled migrant women? Many skilled migrant women are familiar with social exclusion and possess analytical skills equivalent to an academic's. Therefore, the method of participatory workshops was chosen for this research project. Women share and critically analyse their migration histories with the other participants. Workshops are thus not simply 'guided conversations' or 
Riaño, Yvonne (2015): "Minga Biographic Workshops with Highly Skilled Migrant Women: Enhancing Spaces of Inclusion". In: Qualitative Research (QR), Special Issue on Feminist Participatory Methodologies: pp. 1-13. Sage.

focus groups, but rather 'creative environments of experiential learning and intellectual dialogue' (Rogers 2009:127). Minga is an ancient practice of collective community-building work in Andean countries; it means 'building together' in Quechua. The name symbolizes the new knowledge that academics and their research partners can create by working together.

The research partners comprised 57 highly skilled women from countries in Latin America, South-eastern Europe, and the Middle East. When the workshops took place, research partners were between 30 and 50 years old, had been living in Switzerland for an average of eleven years, and were residents of Zurich, Bern, and Aargau — the three most populated German-speaking cantons of Switzerland. Their reasons for moving to Switzerland included study, marriage, or political asylum. Their qualifications included business administration, social sciences, natural sciences, education, law, medical and computer science, architecture, and engineering. Their experience of labour market integration ranged between (1) employed according to their skills, (2) employed below their skills, and (3) unemployed.

Potential partners were contacted using a leaflet describing the collaborative project. The leaflet was distributed among personal contacts as well as among representatives of the Feminist Peace Organisation cfd (Bern) and Migrantinnenraum (Aarau), both NGOs working for the empowerment of migrant women. Respondents expressed a desire to reflect on —and improve —-their situation of professional integration.

Collaborative research projects represent a complex process of communicative interaction; therefore we established a clear, organized and coherent structure for exchange of communication. Workshops that enable dialogue are usually 'the culmination of a long process of group building and interaction' (The Feminist Geography Reading Group 2000:437), so Minga took place in four steps: (a) Minga workshops for collective and comparative data collection, (b) individual conversations, (c) Minga workshops for critical analysis of results, and (d) dissemination of research findings.

\section{Step 1: Minga workshops for collective and comparative data collection}

A total of ten Minga workshops were held over a period of three months, in which all 57 women participated. ${ }^{1}$ The workshops took place at the Institute of Geography of the University of Bern as well as

\footnotetext{
${ }^{1}$ The workshops were conducted in German.
} 
Riaño, Yvonne (2015): "Minga Biographic Workshops with Highly Skilled Migrant Women: Enhancing Spaces of Inclusion". In: Qualitative Research (QR), Special Issue on Feminist Participatory Methodologies: pp. 1-13. Sage.

at the $c f d$ (Bern) and Migrantinnenraum (Aarau). These one-day workshops were conducted in groups of eight to nine women including two academics (Nadia Baghdadi and myself), five to six highly skilled migrant women, and two NGO representatives (Alicia Gamboa and Justina Gospodinov themselves highly skilled migrants). At the beginning of the workshop each participant introduced herself and her expectations of the workshop. The academics provided some initial input to stimulate discussion on perspectives for studying social integration and social exclusion. Participants agreed that a perspective including both the barriers that migrant women face to get access to skilled labour, as well as their resources and coping strategies, was necessary. This perspective has been recognised as innovative, yet is often neglected by researchers (Erel 2009).

Each participant presented her experiences of migration and labour market integration. Each narration was followed by reflection and intense collective debate on barriers and resources. In this way, not only did the women share their own stories but they also participated in analysing others' experiences, were able to put their own professional biography in a comparative context, and reflect on the wider structures of social exclusion.

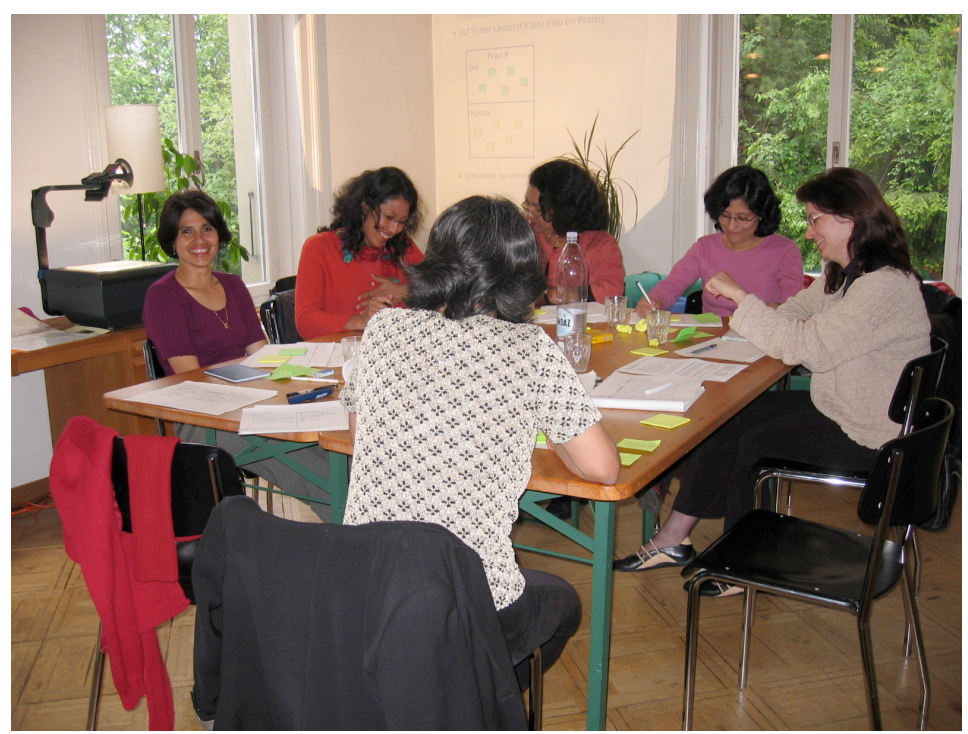

Figure 1. Step 1: Minga Workshops for the presentation and analysis of biographies of professional integration. $^{2}$

\section{Step 2: Individual conversations}

\footnotetext{
${ }^{2}$ Photographs of the workshops are included with participants' consent.
} 
Riaño, Yvonne (2015): "Minga Biographic Workshops with Highly Skilled Migrant Women: Enhancing Spaces of Inclusion". In: Qualitative Research (QR), Special Issue on Feminist Participatory Methodologies: pp. 1-13. Sage.

It could be critically argued that Minga workshops are 'performative' moments, where participants can feel pressured to present their experiences in a manner that will be viewed favourably by others. However, it is widely recognised that the bias of social desirability can occur across a range of qualitative methodologies and survey research (Collins et al 2005), and that methodological strategies need to be implemented to cope with this bias (Ibid). Our strategy was to carry out in-depth individual conversations with workshop participants in order to deepen analysis of their biographies, counteract social desirability, and address sensitive topics that could not be addressed during the workshops. Academics conducted individual conversations with the research partners, starting with both parties agreeing on topics of discussion, followed by detailed recounting by the research partner, and ending with dialogue and analysis of the narrated events.

\section{Step 3: Workshops for the critical analysis of research results}

The first two steps generated a significant amount of data, which then needed to be transcribed, summarized, and analysed. The academics agreed to be in charge of this process, as we were the only ones paid to do so. An initial synthesis and analysis of results was presented to our research partners in two half-day workshops, one in Bern (with 25 participants) and one in Zurich (with 30 participants). Participants received a summary of the presentation in advance, with time to prepare comments. After our presentation participants broke into subgroups of four people, allowing for intense debate. Later a representative of each subgroup presented the results of the analysis to all participants. The strongest critique focused on the categories we proposed to describe different situations of integration into the labour market. The women argued that our proposed categorization was insufficient to describe the variety of experiential situations. This critique was very helpful in enhancing the study's validity. To conclude the workshop, a professional counsellor advised the group about institutions offering support for labour market integration. Furthermore, each participant received a work certificate from the University of Bern recognizing their participation in the research project, a transcript of her personal biography, photographs from the workshops, and the addresses of participants and support institutions in Switzerland. 
Riaño, Yvonne (2015): "Minga Biographic Workshops with Highly Skilled Migrant Women: Enhancing Spaces of Inclusion". In: Qualitative Research (QR), Special Issue on Feminist Participatory Methodologies: pp. 1-13. Sage.

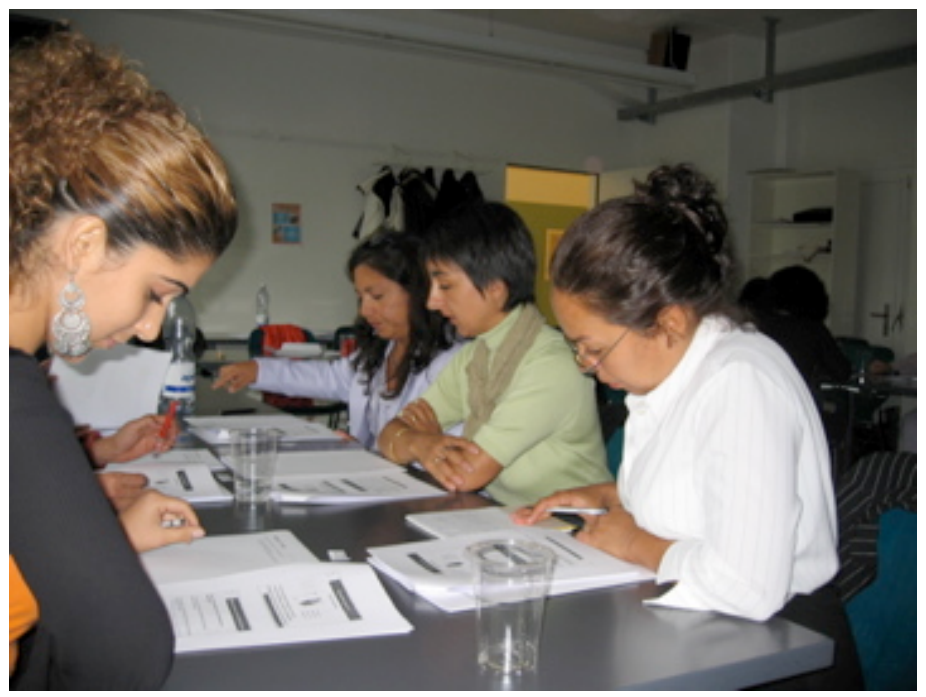

Figure 2. Step 3: Minga workshops for analysis and interpretation of preliminary results.

\section{Step 4: Disseminating research findings}

In the final workshop it was agreed that the academics would prepare a booklet for policymakers summarising the results of our work and offering relevant recommendations. The booklet, titled "Highly skilled migrant women and their prospects of professional integration in Switzerland" (Figure 3), was officially launched at the University of Bern in a ceremony attended by about 100 people, including Minga participants, policymakers, academics, and representatives from migrant organizations and the media. Der Bund, one of Bern's major newspapers, published a full page on the research results (Wenn die Anwältin Salat verpackt, Morgenthaler 2008) (Figure 3). Highly skilled migrant women belonging to the Swiss Green Party used the booklet to launch a petition to the Bern city council requesting action to improve the situation of other women like themselves. The Federal Office for Equality of Women and Men awarded funding to $c f d$ our main NGO partner, to conduct an ongoing mentorship project supporting highly skilled migrant women, which has been scientifically monitored by this paper's author over the past years. 
Riaño, Yvonne (2015): "Minga Biographic Workshops with Highly Skilled Migrant Women: Enhancing Spaces of Inclusion". In: Qualitative Research (QR), Special Issue on Feminist Participatory Methodologies: pp. 1-13. Sage.

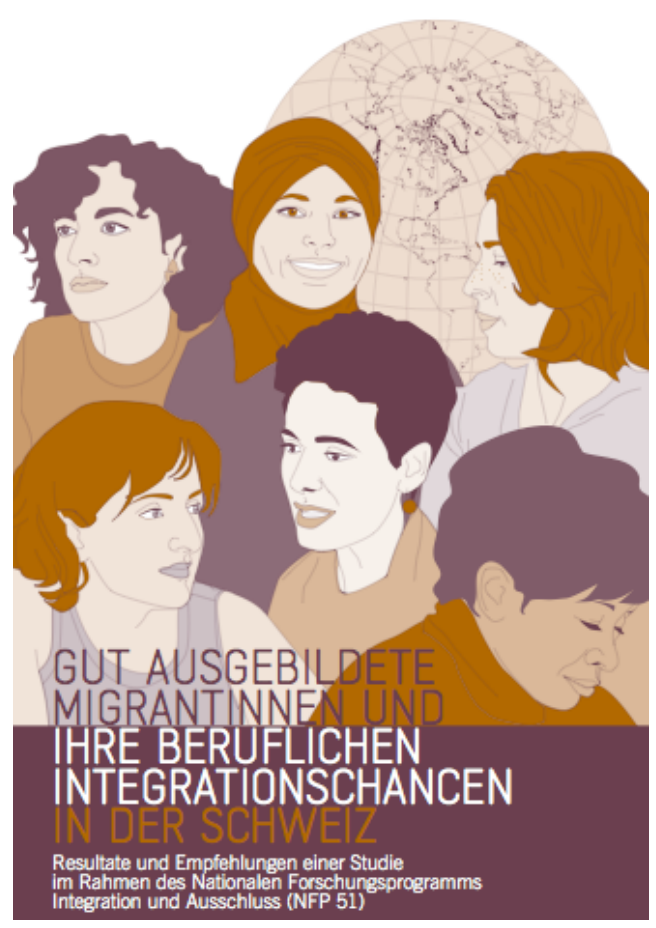

24 Der Buml ARBEIT
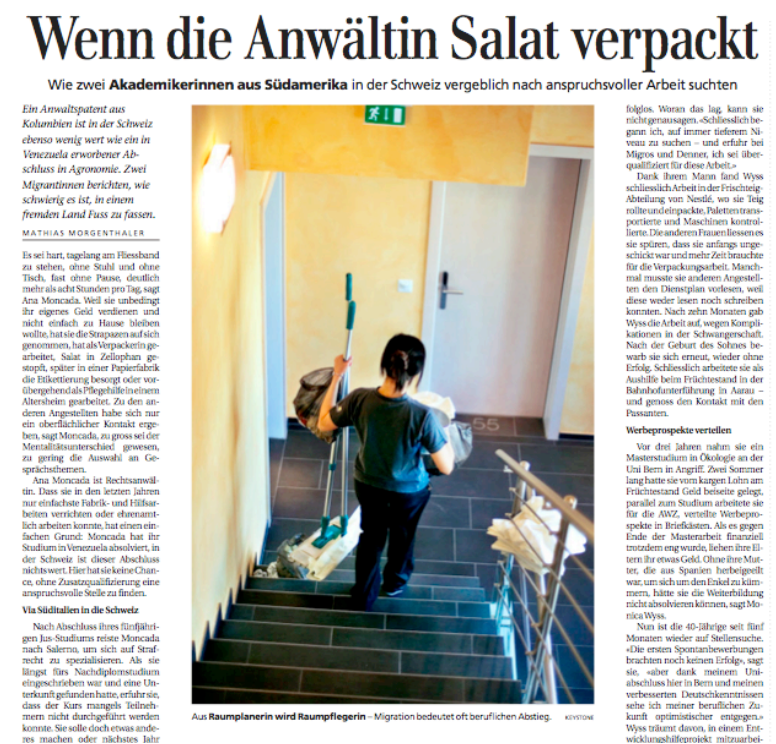

Figure 3. Step 4. Booklet for policymakers; newspaper article in Der Bund.

\section{Studying social exclusion using inclusive methods}

Minga workshops are designed to enhance spaces of inclusion for highly skilled migrant women. The extent to which this goal was fulfilled is illustrated by the following testimonials of participants: ${ }^{3}$

'The Minga workshops were an enriching experience for me. I am convinced that having shared my work experiences with other women in situations similar to my own helped me greatly to move past my fears and frustrations. That is why I feel stronger.' (Alejandra Amacher, business administrator, Mexico.

'I really enjoyed sharing with other women who also have the experience of migration. Women struggled to tell their biographies, and reflect on them, and then make practical recommendations to improve their employment prospects. The work atmosphere was very comfortable. I was also glad to see some women who I had not seen for some time and to meet others.' (Cemyle Özkiran, social worker, Turkey)

\footnotetext{
${ }^{3}$ Names have been changed.
} 
Riaño, Yvonne (2015): "Minga Biographic Workshops with Highly Skilled Migrant Women: Enhancing Spaces of Inclusion". In: Qualitative Research (QR), Special Issue on Feminist Participatory Methodologies: pp. 1-13. Sage.

'The Minga workshops were very fruitful for me. The analysis of my work/life biography allowed me to better evaluate my professional priorities. My confidence in myself and my personal attitudes changed, very much for the better. In practice this means that I became more active in seeking contact with potential employers. The result? I have been invited to interviews for jobs that match my skills. Is that not already a success? The energy we got to both feel and act stronger was amazing.' (Juliana Gygax, sociologist, Peru)

The greatest value of Minga workshops is that they help participants to initiate a process of individual and collective reflection that strengthen their confidence and ability to act. Minga workshops also challenge the dominant discourse that migrant women are uneducated and oppressed individuals who represent a financial burden for the Swiss state. These counter-stories of migrant women as resourceful and motivated individuals can be understood as a struggle for interpretative power (Pratt, 2000) and a form of resistance to oppressive structures (Cahill 2010). Collective work not only increased participants' knowledge about how social exclusion works in practice, but also expanded their social networks. Taking into account these results, Minga workshops can be characterised as spaces of personal transformation. This points to the role of academics as facilitators of personal transformation. This topic has received insufficient attention in participatory research literature (Cahill 2007).

The collaborative spaces of biography collection and analysis afforded by Minga workshops not only had positive social effects, but also produced several scientific insights; for example, that exclusion happens in the domestic sphere as well as the Swiss labour market. Minga also showed that the dynamics of labour market exclusion are set within a broader context of gender relations, which particularly affect migrant women. Furthermore, critical input from participants about their daily experiences helped further differentiate the originally proposed categories of exclusion, suggesting that researchers need to consider the added scientific value of feminist participatory methodologies (cf Francisco 2014).

Participatory research has been criticised for a lack of critical reflection on the merits and limitations of the approach (Kitchin and Hubbard 1999). Minga workshops certainly proved challenging. The political implications of the awareness generated by participatory methods has been recognised, and academics have argued that this can lend momentum to political organizing (Francisco 2014). This momentum was 
Riaño, Yvonne (2015): "Minga Biographic Workshops with Highly Skilled Migrant Women: Enhancing Spaces of Inclusion". In: Qualitative Research (QR), Special Issue on Feminist Participatory Methodologies: pp. 1-13. Sage.

also recognized by one of our research partners: Minga workshops were so successful in creating spaces of critical reflection that she wished to expand them into a politically visible group advocating for the rights of migrant women. However, the disciplining function of structural contexts became apparent: institutional pressure to produce 'cutting edge' research limits the extent to which academics can engage with the politics of social justice. Also, the difficulty of balancing family and professional life in countries with conservative gender regimes like Switzerland (Bühler and Meier Kruker 2002) set further constraints together with the author's precarious academic position, which was only temporary.

The ideal of co-determination proved a vague concept, raising the question of to what extent all participants should engage equally in decision-making during each phase of the research. Minga workshops showed that full co-determination is unrealistic, for several reasons. For a start, the two academics were the only paid participants; this clearly limited the amount of time that the other participants were able to invest, although in certain cases strategies of economic compensation were implemented. In the case of the feminist peace organization's representative, an agreement was reached with her employers to include her time spent co-organizing the workshops in her regular work schedule. I also organised an internship at the Institute of Geography for one of the workshop participants, at her request, for which the Swiss Unemployment Office paid her. Furthermore, only the academics were able to use the Atlas.ti coding system and to structure scientific papers. This division of labour undoubtedly created asymmetries, given that the academics had greater control over the process of analysis and representation. However, constant dialogue between research partners should be considered a key principle of creating inclusionary knowledge-producing spaces.

Minga workshops questioned the idea of migrant women as 'powerless', as the 'powerful' position of academic researchers was constantly contested by research participants. This was clear from the moment we contacted potential participants: some women negotiated their conditions of participation; others refused to participate. Moreover, during the workshops participants made innovative proposals regarding the distribution of roles, the structure of the discussion, the distribution of time, the categories of analysis to be used, and the orientation of specific proposals of action. The power of definition was thus systematically shared among the research partners. We need to move beyond simplistic categorizations of 
Riaño, Yvonne (2015): "Minga Biographic Workshops with Highly Skilled Migrant Women: Enhancing Spaces of Inclusion". In: Qualitative Research (QR), Special Issue on Feminist Participatory Methodologies: pp. 1-13. Sage.

'powerful' and 'non-powerful' subjects (Neal and Mclaughlin 2009). Future researchers must address where, when, and with whom the power lies, in every aspect of research.

\section{Conclusions}

Participatory research neglects highly skilled migrant women living in countries of the global North (Riaño 2011), and migration researchers rarely develop and implement participatory methodologies (Francisco 2014). Inspired by feminist, post-colonial, and participatory perspectives, this paper contributes to the literature by designing — and critically evaluating — the method of participatory Minga workshops. Conceived to create inclusionary spaces of data collection and critical analysis with highly skilled migrant women, its systematic approach can inspire researchers working in different contexts and with different groups.

Using the example of highly skilled migrant women, I have argued that feminist, post-colonial, and participatory approaches need a more complex understanding of 'privilege' and 'power'. For example, highly skilled women may be in a position of power in their native countries, but migrating often implies a loss (or reduction) of that power. Power is clearly related to location; therefore a geographically relational notion of power when defining elites (cf. Smith 2006) is required, as current categorisations of elites seem insufficient to understanding migration dynamics. I have proposed to categorise highly skilled migrant women as 'marginalised elites'.

Moreover, in feminist debates on positionality, researchers have been divided between those having 'more commonalities' or 'less commonalities' with research subjects, which separate or bring them closer (Doyle 1999). Based on the example of highly skilled migrant women, I propose transcending this dualism by acknowledging both commonality and difference in the development of successful research partnerships.

Participatory Minga workshops have enhanced spaces of inclusion for highly skilled migrant women by increasing knowledge of Swiss labour market access, reinforcing self-esteem, helping develop adequate strategies to overcome exclusion, and expanding social networks. Such inclusive spaces are not readily available in Swiss society; therefore I propose viewing participatory Minga workshops as 'spaces of personal transformation'. The knowledge created by Minga workshops challenges the prevailing 
Riaño, Yvonne (2015): "Minga Biographic Workshops with Highly Skilled Migrant Women: Enhancing Spaces of Inclusion". In: Qualitative Research (QR), Special Issue on Feminist Participatory Methodologies: pp. 1-13. Sage.

discourse that migrant women in Swiss society are uneducated and oppressed individuals. These 'counterstories' can be interpreted as a form of resistance that some authors consider a political act (Cahill 2007). Minga workshops also question the idea of migrant women as 'powerless', as the 'powerful' position of academic researchers was contested by research participants.

Participatory methods such as Minga workshops are also challenging. For example, they were so successful in creating spaces of critical reflection that one of our research participants wished to expand them into a politically visible group advocating for the rights of migrant women. But institutional pressure to produce 'cutting edge' research limits the extent to which academics can engage with the politics of social justice. Also, the difficulty of balancing family and professional life in conservative countries like Switzerland set further constraints together with the author's precarious academic position. Feminist participatory methods thus raise important questions: How far are we as academics prepared to go, and how much can (or should) we practically engage with social justice?

Finally, this paper showed that one of the great strengths of feminist participatory methodologies (such as Minga workshops) is to produce greater scientific insight. For example, it was shown that the dynamics of labour market exclusion are set within a broader context of gender relations, which particularly affect migrant women. No information on this topic was previously available. Furthermore, critical input from participants about their daily experiences helped further differentiate the originally proposed categories of exclusion, suggesting that researchers need to closely consider the added scientific value of feminist participatory methodologies (cf Francisco 2014).

\section{Acknowledgements}

I thank my research partners for their enthusiasm, persistence and insights during the Minga work- shops. I also thank two anonymous reviewers for their helpful comments on earlier versions of this article.

\section{Funding}

The author gratefully acknowledges the support of this research by Grant 4051140- 69125 from the Swiss National Science Foundation, National Research Programme 51 on Social Integration and Social Exclusion. 
Riaño, Yvonne (2015): "Minga Biographic Workshops with Highly Skilled Migrant Women: Enhancing Spaces of Inclusion". In: Qualitative Research (QR), Special Issue on Feminist Participatory Methodologies: pp. 1-13. Sage.

\section{References}

Beaverstock J (2005) Transnational elites in the city: British highly-skilled inter-company transferees in New York City's financial district. Journal of Ethnic and Migration Studies 31(2): 245-268.

Bühler E and Meier Kruker V (2002) Gendered labour arrangements in Switzerland: Structures, cultures, meanings: statistical evidence and biographical narratives. Geojournal 56: 305-313.

Cahill C (2007) The personal is political: Developing new subjectivities through participatory action research. Gender, Place \& Culture 14(3): 267-292.

Cahill C (2010) 'Why do they hate us?' Reframing immigration through participatory action research. Area 42(2): 152-161.

Collins M, Shattell M and Thomas SP (2005) An exploration of problematic interviewee behaviors in qualitative research. Western Journal of Nursing Research 27: 188-199.

Doyle L (1999) The Big Issue: empowering homeless women through academic research? Area 31(3): 239-246.

Erel U (2009) Migrant women transforming citizenship. Aldershot: Ashgate.

Francisco V (2014) 'Ang Ating Iisang Kuwento' our collective story: Migrant Filipino workers and participatory action research. Action Research 12(1): 78-93.

Freire P (1970) Pedagogy of the Oppressed. New York: Continuum.

Hopkins P (2007) Thinking critically and creatively about focus groups. Area 39(4): 528-535.

International Organization for Migration (IOM) and OECD Development Centre (2014) Harnessing Knowledge on the Migration of Highly Skilled Women. Geneva: International Organization for Migration.

Jaggar A (2008) Just Methods: An Interdisciplinary Feminist Reader. Boulder: Paradigm Press.

Kesby M, Kindon S and Pain R (2010) Retheorising empowerment and spatialising participatory action research. In: S Kindon, R Pain and M Kesby (eds) Participatory action research approaches and methods. New York: Routledge, pp. 19-25.

Kindon S, Pain R and Kesby M (2010) Connecting people, participation and place. In: S Kindon, R Pain and M Kesby (eds) Participatory action research approaches and methods. New York: Routledge, pp. 1-5.

Kitchin RM and Hubbard P (1999) Research, action and 'critical' geographies. Area 31(3): 195-198.

Letiecq B. and Schmalzbauer L (2012) Community-based participatory research with Mexican migrants in a new rural destination: A good fit? Action Research, 10(3): 244-259. 
Riaño, Yvonne (2015): "Minga Biographic Workshops with Highly Skilled Migrant Women: Enhancing Spaces of Inclusion". In: Qualitative Research (QR), Special Issue on Feminist Participatory Methodologies: pp. 1-13. Sage.

Neal S and Mclaughlin E (2009) Researching Up? Interviews, Emotionality and Policy-Making Elites. Journal of Social Policy 38: 689-707.

Madge C (1993) Boundary disputes: comments on Sidaway (1992). Area 25: 294-299.

Mohanty CT (1991) Cartographies of Struggle. Third World Women and the Politics of Feminism. In: Mohanty CT, Russo A, Torres L (eds.). Third World Women and the Politics of Feminism. Indiana: University Press.

Morgenthaler M (2008) Wenn die Anwältin Salat verpackt [When the lawyer packs salad]. Der Bund, 27 August, 24.

Pain R, Kesby M, and Askins K (2011) Geographies of impact: power, participation and potential. Area 43(2): 183-188.

Pratt G (2000) Participatory action research. In: R Johnston, D Gregory, G Pratt and M Watts. Dictionary of human geography (4th ed). Oxford: Blackwell.

Riaño Y (2011) Drawing New Boundaries of Participation: Experiences and Strategies of Economic Citizenship among Skilled Migrant Women in Switzerland. Environment and Planning A 43: $1530-1546$.

Riaño Y, Limacher K, Aschwanden A, Hirsig S and Wastl-Walter D (2015) Shaping Gender Inequalities: Critical Moments and Critical Places. Equality, Diversity and Inclusion: An International Journal 34(2): 155-167.

Rogers A (2009) The need for practical workshops. Area 42(1): 127-131.

Rose G (1997) Situating knowledges: positionality, reflexivities and other tactics. Progress in Human Geography 21: 305-320.

Sharp J (2005) Geography and Gender: Feminist collaboration in the field. Progress in Human geography 29(3) 304-309.

Smith KE (2006) Problematising power relations in 'elite' interviews. Geoforum 37: 643-653.

The Feminist Geography Reading Group (2000) (Un)doing academic practice: notes from a feminist geography workshop. Gender, Place and Culture 7: 435-439.

Tuhiwai Smith L (1999) Decolonizing Methodologies. Research and Indigenous Peoples. London: Zed Books. 
Riaño, Yvonne (2015): "Minga Biographic Workshops with Highly Skilled Migrant Women: Enhancing Spaces of Inclusion". In: Qualitative Research (QR), Special Issue on Feminist Participatory Methodologies: pp. 1-13. Sage.

\section{Biography}

Yvonne Riaño is a Senior Lecturer at the Institute of Geography of the University of Neuchâtel (Switzerland) and a Research Fellow at the Swiss National Centre of Competence in Research On the move - The Migration-Mobility Nexus. She is considered a leading scholar on issues of skilled migration and gender. Yvonne Riaño writes on participatory research, gender inequalities in the work trajectories of skilled migrants and non-migrants, undocumented migrants and return migration, love migration and transnational marriages, and Latin American migration. She has extensively published in international books and journals. 